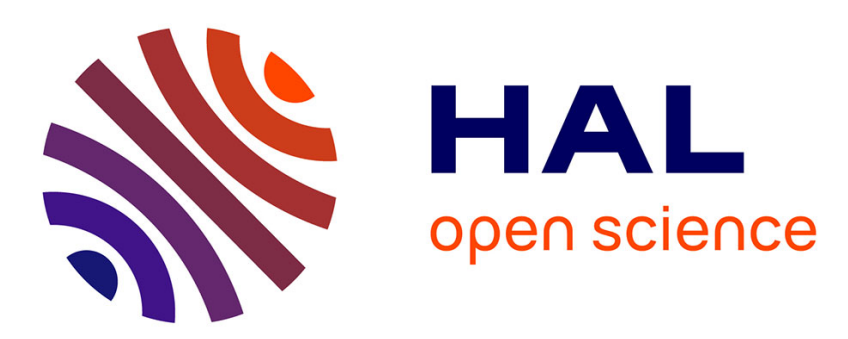

\title{
Large-Scale Oxidation of Multi-Walled Carbon Nanotubes in Fluidized Bed from Ozone-Containing Gas Mixtures
}

Pierre Lassègue, Laure Noé, Jean-Charles Dupin, Marc Monthioux, Brigitte Caussat

\section{To cite this version:}

Pierre Lassègue, Laure Noé, Jean-Charles Dupin, Marc Monthioux, Brigitte Caussat. Large-Scale Oxidation of Multi-Walled Carbon Nanotubes in Fluidized Bed from Ozone-Containing Gas Mixtures. Canadian Journal of Chemical Engineering, 2018, 96 (3), pp.688-695. 10.1002/cjce.23033 . hal01636411

\section{HAL Id: hal-01636411 \\ https://hal.science/hal-01636411}

Submitted on 7 Dec 2021

HAL is a multi-disciplinary open access archive for the deposit and dissemination of scientific research documents, whether they are published or not. The documents may come from teaching and research institutions in France or abroad, or from public or private research centers.
L'archive ouverte pluridisciplinaire HAL, est destinée au dépôt et à la diffusion de documents scientifiques de niveau recherche, publiés ou non, émanant des établissements d'enseignement et de recherche français ou étrangers, des laboratoires publics ou privés. 


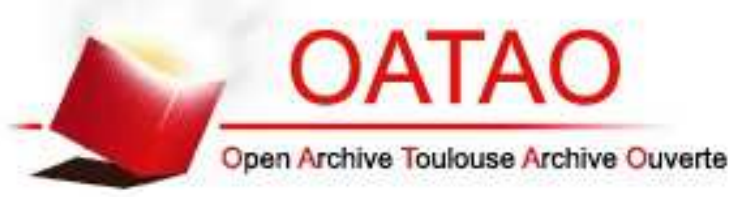

\section{Open Archive TOULOUSE Archive Ouverte (OATAO)}

OATAO is an open access repository that collects the work of Toulouse researchers and makes it freely available over the web where possible.

This is an author-deposited version published in : http://oatao.univ-toulouse.fr/ Eprints ID : 19534

To link to this article : DOI:10.1002/cjce.23033

URL : https://doi.org/10.1002/cjce.23033

\section{To cite this version :}

Lassègue, Pierre $כ$ and Noé, Laure and Dupin, Jean-Charles and Monthioux, Marc and Caussat, Brigitte $\stackrel{\omega}{-2}$ Large-Scale Oxidation of Multi-Walled Carbon Nanotubes in Fluidized Bed from OzoneContaining Gas Mixtures. (2018) The Canadian Journal of Chemical Engineering, vol. $96\left(\mathrm{n}^{\circ} 3\right)$. pp. 688-695. ISSN 0008-4034

Any correspondence concerning this service should be sent to the repository administrator: staff-oatao@ listes-diff.inp-toulouse.fr 


\title{
LARGE-SCALE OXIDATION OF MULTI-WALLED CARBON NANOTUBES IN FLUIDIZED BED FROM OZONE-CONTAINING GAS MIXTURES
}

\author{
Pierre Lassègue, ${ }^{1}$ Laure Noé, ${ }^{2}$ Jean-Charles Dupin, ${ }^{3}$ Marc Monthioux ${ }^{2}$ and Brigitte Caussat ${ }^{1}$ * \\ 1. Laboratoire de Génie Chimique, Université de Toulouse, CNRS, INPT, UPS, Toulouse, France \\ 2. Centre d'Elaboration de Matériaux et d'Etudes Structurales, CNRS, Toulouse, France \\ 3. Institut des Sciences Analytiques et de Physico-Chimie pour I'Environnement et les Matériaux, UPPA, Pau, France
}

\begin{abstract}
$100 \mathrm{~g}$ of multi-walled carbon nanotubes (MWCNTs) tangled in balls of $388 \mu \mathrm{m}$ in Sauter diameter were treated per run in a pre-industrial scale fluidized bed reactor, using ozone-based gaseous mixtures at ambient temperature. The influence of ozone concentration and of the addition of water vapour was studied, for treatment durations between $1 \mathrm{~h}$ and $20 \mathrm{~h}$. The process behaviour was analyzed in terms of fluidized bed pressure drop and temperature profile. The nature and amount of the grafted oxygen based functions were analyzed, as the structural modifications created. An oxidation mechanism in two steps was evidenced, showing the grafting of hydroxyl, phenol, and ether functions in a first step and then of lactone, quinone, carbonyl, and carboxylic groups. A moderate etching of the MWCNT outer walls was observed. The amount of grafted functions and of structural defects increased with treatment duration and was highly exalted by the presence of water vapour. All the results obtained showed that the oxidation was uniform on the whole powder of the bed and from the outer part to the centre of the balls, probably thanks to the high fluidization quality maintained all along the ozone treatment.
\end{abstract}

Keywords: multi-walled carbon nanotubes, oxidation, fluidization, ozone, water vapour

\section{INTRODUCTION}

$\mathrm{C}$ arbon nanotubes (CNTs) have potential applications in many fields, including composite materials, energy storage, electronics, catalysis, etc. ${ }^{[1-4]}$ Multi-walled CNTs (MWCNTs) are today produced at large scale under the form of powders by various companies at relatively low cost. ${ }^{[5]}$ However, the surface of the as-produced MWCNTs is hydrophobic and chemically inert, which limits their large-scale applications. ${ }^{[6]}$ This is particularly true in the field of composite materials, for which the MWCNT inertness leads to low dispersion in the polymer matrix and weak interfacial bonding. ${ }^{[7-8]}$

It is now established that the oxidation of MWCNTs is an efficient way to overcome these limitations and also to enhance their surface reactivity for catalysis and other surface dependent applications. ${ }^{[7-10]}$ At lab scale, oxidation by exposure to liquid concentrated acids is very popular and has proved to be efficient in improving composite properties and MWCNT surface reactivity for further functionalization. ${ }^{[9,11-14]}$ But the liquid wastes and the noxious gases generated by this wet oxidation method, as well as the necessity to repeatedly wash and dry the CNTs, are not suited for industrial use. ${ }^{[1-14]}$ Gas phase oxidation is much cleaner, it only involves one step and can be operated at large scale using appropriate processes. ${ }^{[9,14]}$ Some studies about gas phase oxidation of MWCNTs using either air ${ }^{[15]}$ or nitric acid vapours ${ }^{[16-18]}$ at high temperature have led to mitigated results: the CNTs were highly structurally damaged or even partially burnt. Ozone presents significant advantages, since it can be produced easily at large-scale and low cost and it decomposes into $\mathrm{O}_{2}$ upon reaction with unsaturated molecules. ${ }^{[9,10-14]}$ Moreover, the treatment can be performed at ambient temperature thanks to the high reactivity of ozone. ${ }^{[9]}$ Numerous works have shown that dry ozone treatments can remove the amorphous carbon, graft oxygen-containing groups such as hydroxyl or carboxylic bonds on the surface of MWCNTs, and locally etch the CNT outer walls, leading to improved dispersion and better interfacial bonding to the polymer matrix. ${ }^{[7,8,19]}$ By using $9 \mathrm{~cm}^{3}$ of $\mathrm{O}_{3}$ diluted in $\mathrm{O}_{2}$ per min and per $\mathrm{g}$ of MWCNTs, Xia et al. ${ }^{[9]}$ succeeded in grafting about $6.5 \mathrm{wt} \%$ of oxygen atoms after $5 \mathrm{~h}$ of treatment. They observed an etching of the amorphous carbon attached to the MWCNT outer walls after $3 \mathrm{~h}$, whereas for $9 \mathrm{~h}$ the CNT caps were opened, resulting in a significant weight loss of $23 \%$. The addition of water vapour to ozone allows intensifying and accelerating the oxygen grafting by creating hydroxyl radicals $\left(\mathrm{OH}^{*}\right)$ in the gas phase. ${ }^{[10]}$ Indeed, by using $80 \mathrm{~cm}^{3}$ of $\mathrm{O}_{3}$ diluted in $\mathrm{O}_{2}$ per min and per $\mathrm{g}$ of CNTs, Peng et al. ${ }^{[10]}$ showed that the addition of water vapour allows doubling the amount of grafted oxygen-based functions from $9 \mathrm{wt} \%$ to $18 \mathrm{wt} \%$ after $2 \mathrm{~h}$, however with a larger alteration of the MWCNT structure caused by the addition of water vapour.

It is worth noting that all these studies have treated very low weights of MWCNTs, generally of the milligram-scale, and not higher than $2 \mathrm{~g}$, by using lab-scale homemade glass reactors in which the contact between the gas phase and the MWCNTs powder is not really controlled. Gas-solid fluidized bed reactors consist of vertical cylindrical columns in which the powder is maintained at rest by a porous plate, and the gas flows vertically upward through the bed of powder. ${ }^{[20-24]}$ Within an appropriate range of bed dimensions and gas flow rates, the powder is put in

* Author to whom correspondence may be addressed.

E-mail address: brigitte.caussat@ensiacet.fr 
suspension into the gas, and an intense gas-solid mixing appears, increasing the interphase thermal and mass transfer rates. This explains why fluidized bed reactors are well-known to produce uniform powder treatments. ${ }^{[22-24]}$ As a consequence, they have been intensively used at the multi-ton scale in the chemical and polymer industries for fifty years. ${ }^{[24]}$ Vennerbeg et al. ${ }^{[14]}$ successfully oxidized MWCNTs by an ozone/oxygen mixture in a mini fluidized bed (containing only $1 \mathrm{~g}$ of MWCNTs). After a few tens of minutes of treatment, by using $56 \mathrm{~cm}^{3}$ of ozone diluted in oxygen per min and per gram of MWCNTs, significant levels of oxidation (8 at.\% 0 ) were achieved, with little damage to the nanotube walls.

In the present work, we report the ozone treatment of $100 \mathrm{~g}$ of MWCNTs in a pre-industrial scale fluidized-bed reactor at ambient temperature and atmospheric pressure. In comparison with the previous studies of the literature, such a high weight of MWCNTs treated per run is fully original. Two ozone concentrations in oxygen were tested, as well as the addition of water vapour. Treatment durations between $1 \mathrm{~h}$ and $20 \mathrm{~h}$ have been studied. The process behaviour was analyzed in terms of fluidized bed pressure drop and temperature profiles. The nature and amount of the grafted oxygen-based functions on the MWCNT surface were analyzed, as well as the resulting structural modifications.

\section{EXPERIMENTAL}

The experimental setup (Figure 1) is composed of a vertical stainless steel fluidization column $(8.3 \mathrm{~cm}$ in internal diameter

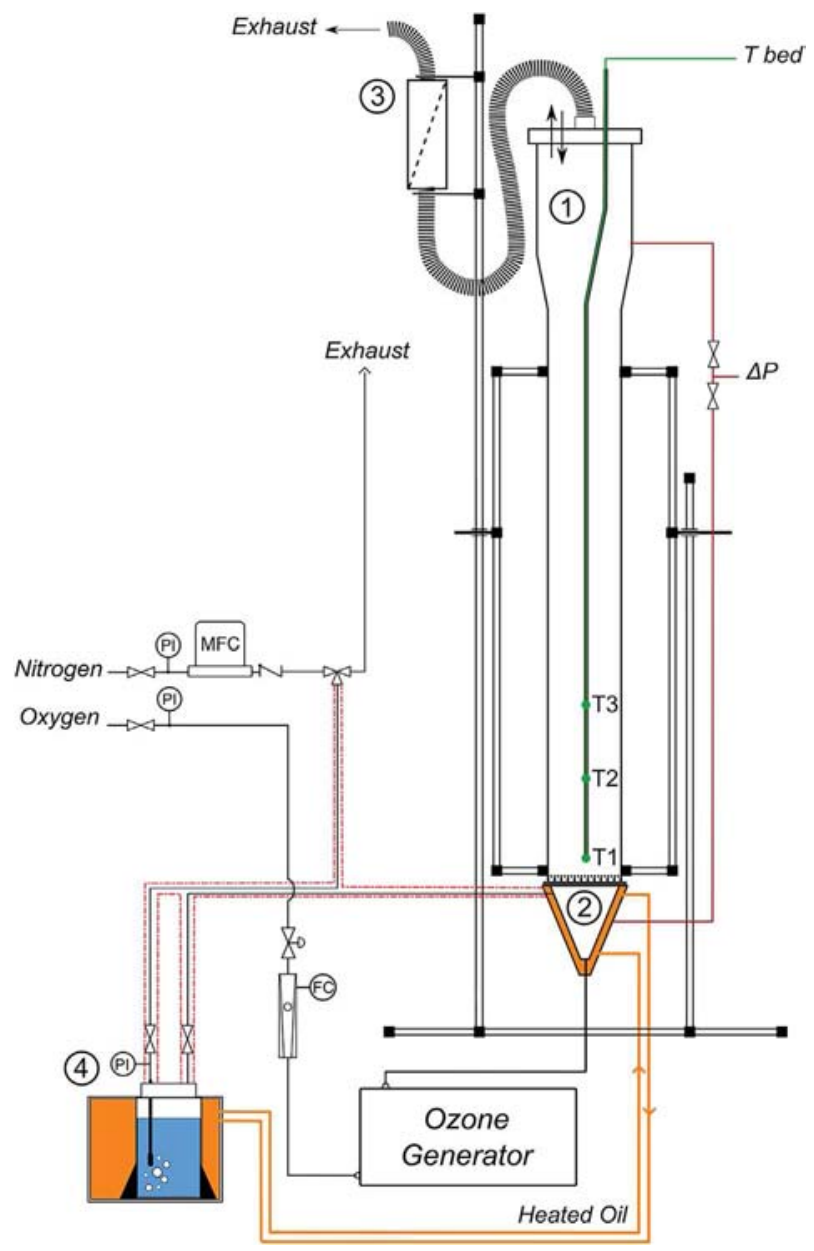

Figure 1. Scheme of the experimental setup. and $1 \mathrm{~m}$ in height - noted 1 in Figure 1). It is equipped with a distributor consisting of a perforated steel plate to provide a homogeneous gas distribution (noted 2). The double-wall conical zone of the gas inlet is pre-heated by the circulation of thermostatted oil when water vapour is used. An enlarged zone ( $16 \mathrm{~cm}$ in diameter and $40 \mathrm{~cm}$ in height) is present at the top of the column in order to reduce powder elutriation. A high performance HEPA13 filtration cartridge (noted 3 ) is placed at the exit of the column to collect any elutriated particles. Three K-type thermocouples $\mathrm{T} 1, \mathrm{~T} 2$, and $\mathrm{T} 3$ are fixed in a steel tube along the vertical axis of the reactor, respectively at 6,12 , and $21 \mathrm{~cm}$ above the distributor, to measure the temperature of the fluidized bed during ozonation. A differential pressure sensor (Unik 5000; Druck Ltd.) with taps under the distributor and at the top of the reactor allows measuring the fluidized bed pressure drop. The temperatures and pressure are monitored in real time by a Minitrend ${ }^{\mathbb{R}} \mathrm{QX}$ (Honeywell) device and treated by the TrendServer Pro software (6.1.41 version, Honeywell).

An ozone generator (Lab2B, Ozonia) is connected to the bottom of the column and is fed with pure oxygen (Alphagaz oxygen, Air Liquide), ensuring an ozone concentration up to a maximum of $10 \mathrm{~g} \cdot \mathrm{h}^{-1}$. The oxygen flow rate is controlled by a ball rotameter (GT1355, R-2-15-B, Brooks Instrument).

For some experiments, a bubbler (noted 4) containing distilled water is placed in a thermostatted oil bath maintained at $50{ }^{\circ} \mathrm{C}$ and is fed with nitrogen ( $\mathrm{N}_{2}, \mathrm{~N} 50$ Alphagaz 1, Air Liquide) to transport the water vapour. The flow rate of nitrogen is regulated by a mass flow controller (FC-7700CU, Aera) and the nitrogen line is heated by heating ribbons to avoid any recondensation of water vapour. All the experiments were performed at atmospheric pressure and ambient temperature.

An adimensional bed pressure drop $\Delta \mathrm{P}^{*}$ is calculated as the ratio between the experimentally measured bed pressure drop and the theoretical one, corresponding to the bed weight divided by the column surface area. To obtain the experimental bed pressure drop, the distributor pressure drop must be removed to the measured pressure drop. When the fluidization is reached, a horizontal plateau appears for which $\Delta \mathrm{P}^{*}$ is equal to $1 .^{[24]}$

Multi-walled carbon nanotubes (Graphistrength ${ }^{\mathbb{R}} \mathrm{C} 100$; Arkema) were used without any purification treatment. As can be seen in Figures $2 a$ and $2 b$, they are entangled under the form of coarsely spherical balls of $388 \mu \mathrm{m}$ in Sauter diameter. Nanotube walls are made of 10-15 concentric graphenes with a mean external diameter of $12 \mathrm{~nm}$. Some amorphous carbon is present on the walls and internal defects are visible (Figure $2 \mathrm{c}$ and $2 \mathrm{~d}$ ). Their intrinsic iron content determined by ICP-MS is $1.35 \pm 0.06 \mathrm{wt} \%$. Their skeleton density is $2027 \mathrm{~kg} \cdot \mathrm{m}^{-3}$. The grain density of the MWCNT balls was estimated at $\sim 180 \mathrm{~kg} \cdot \mathrm{m}^{-3}$ and their untapped density is equal to $90 \mathrm{~kg} \cdot \mathrm{m}^{-3}$. These MWCNT balls display very good fluidization performances, as found by other authors. ${ }^{[20,21]}$ The minimum fluidization velocity $U_{m f}$ of the MWCNT balls measured at ambient temperature under nitrogen is equal to $1.2 \mathrm{~cm} \cdot \mathrm{s}^{-1}$.

MWCNTs were analyzed before and after ozone pre-treatment by several characterization techniques. The powder morphology was observed by Field Emission Gun Scanning Electron Microscopy (FEG-SEM) on a Jeol JSM-7100F, and by High Resolution Transmission Electron Microscopy (HRTEM) using a CM30 (Philips) with $\mathrm{LaB}_{6}$ gun operated at $150 \mathrm{kV}$ to minimize damaging irradiation effects. Before the HRTEM observations, MWCNTs were sonicated during $15 \mathrm{~min}$ in ethanol. Sonication was carried out using the bath method, which is much less energetic than the sonoprobe method. As a result, as can be seen in Figure $2 c$, the 

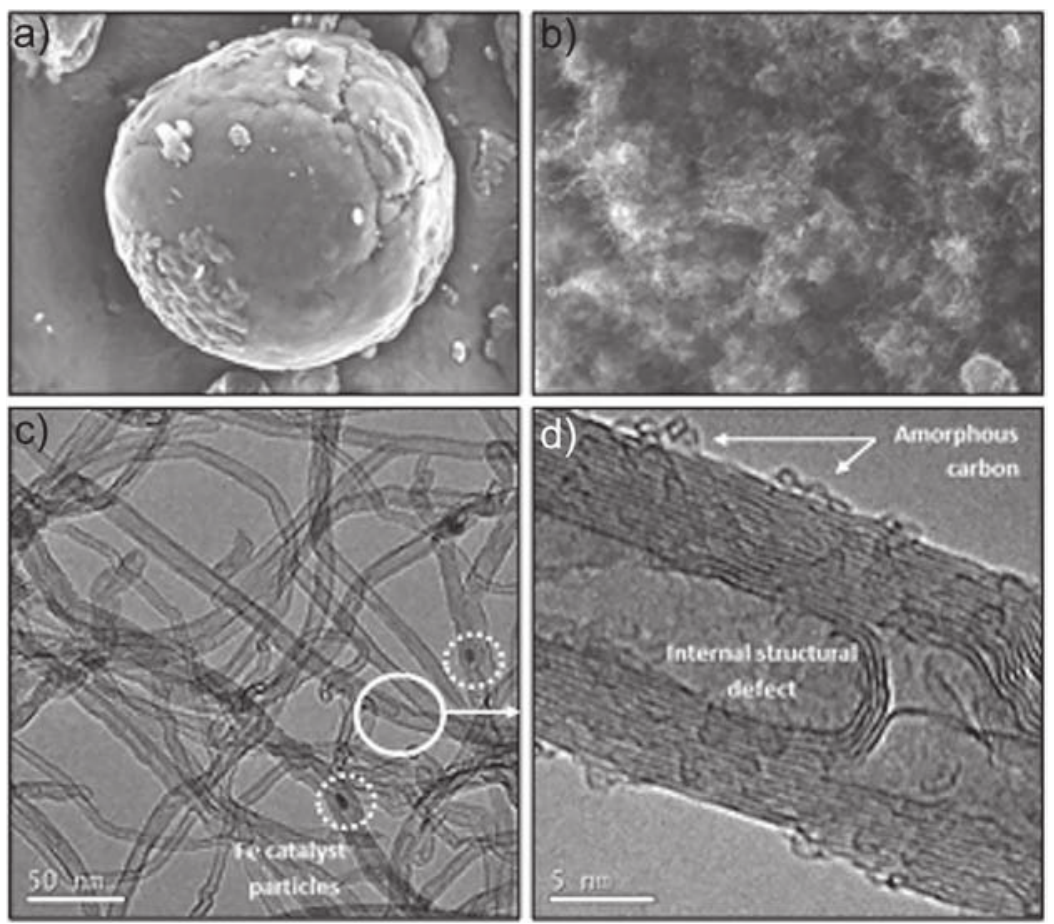

Figure 2. SEM and (HR-)TEM views of the raw MWCNTs. Some of the amorphous carbon exhibit the morphology and dimensions of fullerenes.

nanotubes are highly dispersed and their structural integrity is not affected by the sonication. No treatment of MWCNTs was realized before FEG-SEM analysis.

IR spectroscopy analyses were performed on a FT-NIR/MIR Frontier (Perkin Elmer) spectrometer. The MWCNTs were ground and pressed into a pellet of potassium bromide $(\mathrm{KBr})$ and scanned from 4000 to $400 \mathrm{~cm}^{-1}$ with a resolution of $4 \mathrm{~cm}^{-1}$. X-ray Photoelectron Spectroscopy (XPS) measurements were carried out in a K-alpha ${ }^{+}$(Thermo Scientific) setup equipped with an $\mathrm{Al}$ monochromatic $\mathrm{K} \alpha$ source emitting at $1486.6 \mathrm{eV}$. Thermo-Gravimetric Analyses (TGA) were performed using a thermobalance Q600 (TA Instruments) under $100 \mathrm{sccm}\left(\mathrm{cm}^{3} / \mathrm{min}\right.$ at standard temperature and pressure) of nitrogen with a thermal ramp of $10{ }^{\circ} \mathrm{C} \cdot \mathrm{min}^{-1}$.

The operating conditions tested are detailed in Table $1.100 \mathrm{~g}$ of MWCNTs were used for each experiment, corresponding to a ratio between the fixed bed height and the reactor diameter of 2.3. Such a ratio is necessary to ensure good mass transfer between the gas and the powder and then a uniform treatment. ${ }^{[24]}$ Two fluidization ratios $U / U_{m f}$ were tested in order to analyze the influence of the residence time of the gas into the bed and of the gas/solid mixing intensity. This led to two different volume percentages of ozone in the inlet gas. The influence of the presence of water vapour was studied for the highest fluidization ratio studied. Various treatment durations were tested, between $1 \mathrm{~h}$ and $20 \mathrm{~h}$. The

\begin{tabular}{l} 
Table 1. Operating conditions tested \\
\hline
\end{tabular}

volume percentage of water vapour was calculated assuming that saturation is reached in the bubbler. Let us note that we used for these runs around $0.8 \mathrm{~cm}^{3}$ of $\mathrm{O}_{3}$ diluted in $\mathrm{O}_{2}$ per min and per $\mathrm{g}$ of CNTs, which is a value 10 to 100 times lower than those used by previous authors. ${ }^{[9,10,14]}$

\section{RESULTS AND DISCUSSION}

\section{Process Behaviour}

The temporal evolutions of the bed adimensional pressure drop $\left(\Delta \mathrm{P}^{*}\right)$ and temperatures are given in Figure 3 for runs $03-1$ and O3-W. The arrows correspond to the sampling of MWCNTs (roughly $200 \mathrm{mg}$ each), which necessitates to cut off the gas supply, leading to a decrease of the bed pressure drop and temperatures. The main observation concerns the increase of temperature during ozonation, of $20 \pm 2{ }^{\circ} \mathrm{C}$ without $\mathrm{H}_{2} \mathrm{O}$ and of $45 \pm 2{ }^{\circ} \mathrm{C}$ with $\mathrm{H}_{2} \mathrm{O}$. To the best of our knowledge, this increase of temperature is not mentioned in the works about MWCNT ozonation, probably because the authors have not placed any thermocouple in the ozonation setup. It is well known that the oxidation of CNTs in the presence of oxygen is exothermic. ${ }^{[23,25]}$ With $\mathrm{H}_{2} \mathrm{O}$, our results show that this exothermicity is enhanced, probably because of the formation of hydroxyl radicals $\left(\mathrm{OH}^{*}\right)$ in the gas phase which could be more active for oxidizing MWCNTs walls than the species existing in the $\mathrm{O}_{2} / \mathrm{O}_{3}$ mixture. During the first $3 \mathrm{~h}$, the bed temperatures continue to increase until reaching a steady state. This quite long transitory step is due to the heat exchange with the reactor walls which are not thermally insulated and to the inertia of the steel reactor.

It is worth noting that for the runs with $\mathrm{U} / \mathrm{U}_{\mathrm{mf}}$ equal to 9 (runs 03-2 and $\mathrm{O} 3 \mathrm{~W}$ ), the $\mathrm{T} 2$ temperature is closer to $\mathrm{T} 3$ than to T1 whereas for the run with $\mathrm{U} / \mathrm{U}_{\mathrm{mf}}$ close to 1.2 (run 03-1), $\mathrm{T} 2$ is closer to $\mathrm{T} 1$ than to T3. This can be explained by the fact that with a high fluidization ratio, the bed is fluidized in the turbulent regime with jets of powder existing in its upper part (called the splash zone ${ }^{[26]}$ ). As a consequence, the thermocouple $\mathrm{T} 2$ is in the splash zone of the 

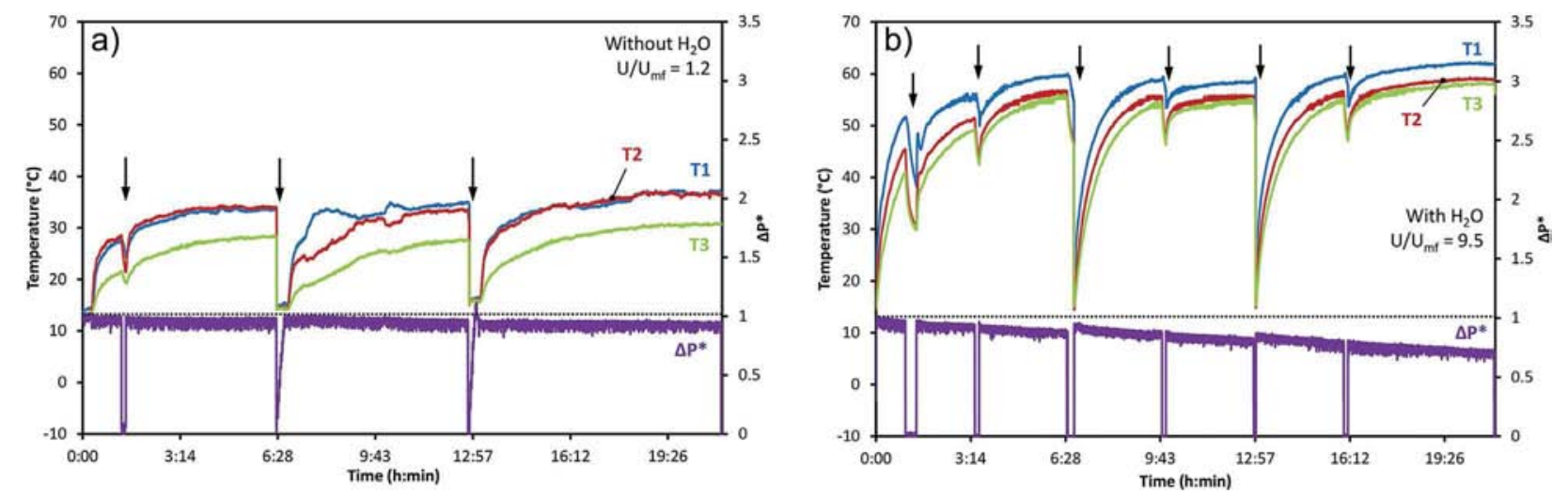

Figure 3. Adimensional bed pressure drop $\left(\Delta \mathrm{P}^{*}\right)$ and temperature profiles during (a) run O3-1 and (b) run O3W until $20 \mathrm{~h}$.

bed as T3, i.e. in direct vision of the cold reactor walls. At a low fluidization ratio, $\mathrm{T} 2$ is in the dense region of the bed as $\mathrm{T} 1$, and only $\mathrm{T} 3$ is present in the splash zone. The fact that even for this low fluidization ratio, $\mathrm{T} 1$ and $\mathrm{T} 2$ are very close to each other means that the bed was fully fluidized.

This conclusion can also be drawn from the adimensional bed pressure drop values, which are close to 1 at the beginning of the ozonation process. Then, $\Delta \mathrm{P}^{*}$ slightly decreases with time due to powder sampling, elutriation, and MWCNTs etching. This decrease is more pronounced in the presence of water (run $\mathrm{O} 3 \mathrm{~W}$ ), due to more intense etching. Indeed, for this run, a weight loss of the bed equal to $19.5 \mathrm{~g}$ was measured after $20 \mathrm{~h}$ of treatment, which can be partly attributed to MWCNT etching. For the entire run duration, elutriation is close to $2.5 \mathrm{~g}$ for $\mathrm{U} / \mathrm{U}_{\mathrm{mf}}=9$ (runs 03-2 and $03 \mathrm{~W}$ ) and to $1.7 \mathrm{~g}$ for $\mathrm{U} / \mathrm{U}_{\mathrm{mf}}=1.2$ (run 03-1).

\section{XPS and FTIR Spectroscopy Results}

The 01s XPS spectra before and after treatment are given in Figure 4 for runs 03-2 and O3W. For the raw CNTs, the 01s signals between 531 and $533 \mathrm{eV}$ are in the background noise. For run O3W, Figure 4 indicates that after $1 \mathrm{~h}$ of treatment, the $01 \mathrm{~s}$ peaks relative to $\mathrm{C}=\mathrm{O}(531.5 \mathrm{eV})$ and $\mathrm{C}-\mathrm{O}$ bonds $(533 \mathrm{eV})$ are present. The peak at $533 \mathrm{eV}$ is slightly higher than that at $531.5 \mathrm{eV}$, meaning that the $\mathrm{C}-\mathrm{O}$ bonds, existing in ether, hydroxyl, and phenol functions, are favoured for small treatment times. The intensity of the two peaks, hence the amount of grafted oxygen species, increases until $12 \mathrm{~h}$. The dominant peak is still that of $\mathrm{C}-\mathrm{O}$ bonds after $6 \mathrm{~h}$. After $12 \mathrm{~h}$, the $\mathrm{C}-\mathrm{O}$ and $\mathrm{C}=0$ peaks are of similar intensity. For $20 \mathrm{~h}$, the $\mathrm{C}-\mathrm{O}$ signal is more intense, which could be due to an evolution of the grafted functions or to a re-arrangement of the $\mathrm{O}$ atoms. So, from $6 \mathrm{~h}$, more complex functions are grafted such as carboxylic acid, carbonyl, lactone, quinone, or carboxylic anhydride groups. This result is in agreement with those of Vennerberg et al. ${ }^{[14]}$ and of Xia et al. ${ }^{[9]}$ who found that the oxidation of MWCNTs from ozone/oxygen mixtures begins by the grafting of simple hydroxyl functions which are then further oxidized into more complex groups. Hydrogen of the $\mathrm{OH}$ groups can mainly proceed from the adsorbed water present on the nanotube surface, since nanotubes have been put into the fluidized bed reactor under ambient air and they have not been dried before ozone treatment.

Figure 4 indicates that after $20 \mathrm{~h}$, the 01 s peaks are much lower without water (run 03-2), confirming that the presence of $\mathrm{H}_{2} \mathrm{O}$ largely enhances the efficiency of the oxidation process, as found by Peng et al., ${ }^{[10]}$ probably due to the presence of more reactive hydroxyl radicals in the gas phase. Moreover, for run O3-2, the peak at $533 \mathrm{eV}$ is much more intense than that at
$531.5 \mathrm{eV}$, revealing that the $\mathrm{O}_{2} / \mathrm{O}_{3}$ mixture favours the grafting of ether, hydroxyl, and phenol functions.

Three $\mathrm{KBr}$ pellets containing ground MWCNT balls were prepared and analyzed by FTIR for each sample. It is to be noted that the spectra obtained are similar for the three analyses, meaning that the treatment is uniform on the whole powder of the bed and also from the outer part to the centre of the MWCNT balls. This implies that the fluidized bed provides efficient gas-solid mixing and that the transport rate of the gaseous reactive species inside the porous medium constituted by the MWCNT balls is high enough to ensure a uniform treatment of the entire MWCNT outer surface.

Figure 5 presents the FTIR spectra obtained before and after runs 03-1, 03-2 (without $\mathrm{H}_{2} \mathrm{O}$ ), and $\mathrm{O} 3 \mathrm{~W}$ (with $\mathrm{H}_{2} \mathrm{O}$ ) for various

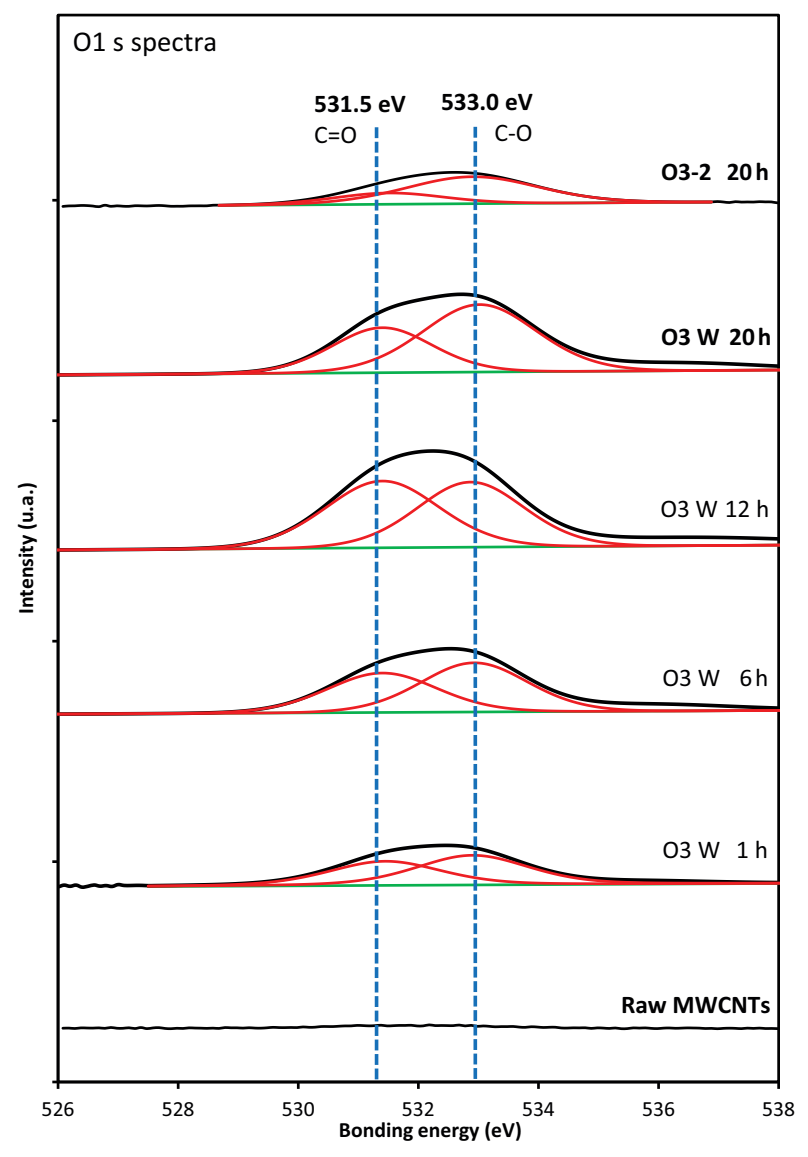

Figure 4. O1s XPS spectra before and after runs O3-2 and O3 W. 
treatment durations. Eight peaks are present on the spectrum of the raw CNTs. The peaks at $3430-3440 \mathrm{~cm}^{-1}$ and $1635 \mathrm{~cm}^{-1}$ are representative of water molecules adsorbed on the MWCNT surfaces and also into the $\mathrm{KBr}$ which is highly hydrophilic. ${ }^{[14,27]}$ The double peak at 2970 and $2920 \mathrm{~cm}^{-1}$ is related to aliphatic C-H elongations and is then characteristic of impurities present on the MWCNT surface, mainly linked to the synthesis process. ${ }^{[14,27-29]}$ At $1580 \mathrm{~cm}^{-1}$ a shoulder characteristic of $\mathrm{C}=\mathrm{C}$ elongations appears and then of carbon nanotubes. ${ }^{[10,14,29-31]}$ Finally, two peaks at 1094 and $1040 \mathrm{~cm}^{-1}$ can be distinguished on the large signal between 930 and $1200 \mathrm{~cm}^{-1}$, characteristic of $\mathrm{C}-\mathrm{O}$ and $\mathrm{O}-\mathrm{H}$ bonds, most likely belonging to phenol and hydroxyl groups, related to a small contamination of the raw MWCNTs. ${ }^{[10,28,32]}$

For run $03 \mathrm{~W}$ (Figure 5a), after $1 \mathrm{~h}$, a higher intensity is observed for the signal between 930 and $1200 \mathrm{~cm}^{-1}$. As previously said, it corresponds mainly to simple hydroxyl and phenol functions. A shift at $1140 \mathrm{~cm}^{-1}$ can be isolated which probably corresponds to ether functions. ${ }^{[14]}$ The peak at $1389 \mathrm{~cm}^{-1}$ has been assigned to impurities present in the $\mathrm{KBr}$. After $6 \mathrm{~h}$, a shift at $1702 \mathrm{~cm}^{-1}$ appears, characteristic of more complex functions (carboxylic acid, aldehyde, ketone, ester, or carboxylic anhydride groups or quinone or lactone groups). ${ }^{[29,33,34]}$ After $12 \mathrm{~h}$, the peaks at $1040 \mathrm{~cm}^{-1}$ and $1092 \mathrm{~cm}^{-1}$ are more intense whereas the shift at $1140 \mathrm{~cm}^{-1}$ decreases, confirming the XPS results about the formation of more complex functions such as esters. ${ }^{[31]}$ The peak close to $2980 \mathrm{~cm}^{-1}$ associated to the $\mathrm{sp}^{3}$ carbon and then to structural defects of MWCNTs slightly increases, which could mean that the etching process becomes sensitive after $6 \mathrm{~h}$ of treatment. After $20 \mathrm{~h}$, a decrease of the peaks at $1040 \mathrm{~cm}^{-1}$ and $1092 \mathrm{~cm}^{-1}$ relative to hydroxyl and phenol groups is observed, whereas the peaks at
$1140 \mathrm{~cm}^{-1}$ and $1702 \mathrm{~cm}^{-1}$ remain constant. This could be due to the transformation of ester groups into ether functions. ${ }^{[35]}$

A similar evolution of the spectra is observed after $1 \mathrm{~h}$ of treatment for run 03-2 (Figure 5b). The results are different after $6 \mathrm{~h}$, since the signal between 930 and $1200 \mathrm{~cm}^{-1}$ still increases, meaning that new simple functions such as hydroxyl, phenol, and ether are grafted. After $12 \mathrm{~h}$, the intensity of this signal decreases and a new peak appears at $1740 \mathrm{~cm}^{-1}$, corresponding to the $\mathrm{C}=\mathrm{O}$ elongation. As for run O3W, the hydroxyl, phenol, and ether groups are oxidized in more complex functions, but less markedly due to the absence of water. After $20 \mathrm{~h}$, peaks at 879 and $1047 \mathrm{~cm}^{-1}$ are more intense and the other signals between 930 and $1200 \mathrm{~cm}^{-1}$ and at $1740 \mathrm{~cm}^{-1}$ remain constant. A possible explanation is that new $\mathrm{C}-\mathrm{O}$ bonds are formed thanks to the formation of new structural defects on the MWCNT surface.

For run 03-1 (Figure 5c), so with a higher ozone concentration than for run 03-2, similar trends can be observed with however a more rapid apparition of $\mathrm{C}=\mathrm{O}$ bonds from $6 \mathrm{~h}$ (peak at $1782 \mathrm{~cm}^{-1}$ ). The intensity of this peak increases until $20 \mathrm{~h}$ whereas the $930-1200 \mathrm{~cm}^{-1}$ signal intensity decreases. So a higher ozone concentration seems to favour the formation of complex oxygen functions.

\section{HRTEM Results}

Figure 6 presents representative HRTEM images of MWCNTs after the 3 runs for 1,12 , and $20 \mathrm{~h}$ of treatment. Many $(\sim 30-50)$ HRTEM micrographs were taken for each run, all revealing similar results. This confirms that the oxidative process is uniform for all the MWCNT balls present in the fluidized bed and also from the outer part to the centre of the balls.
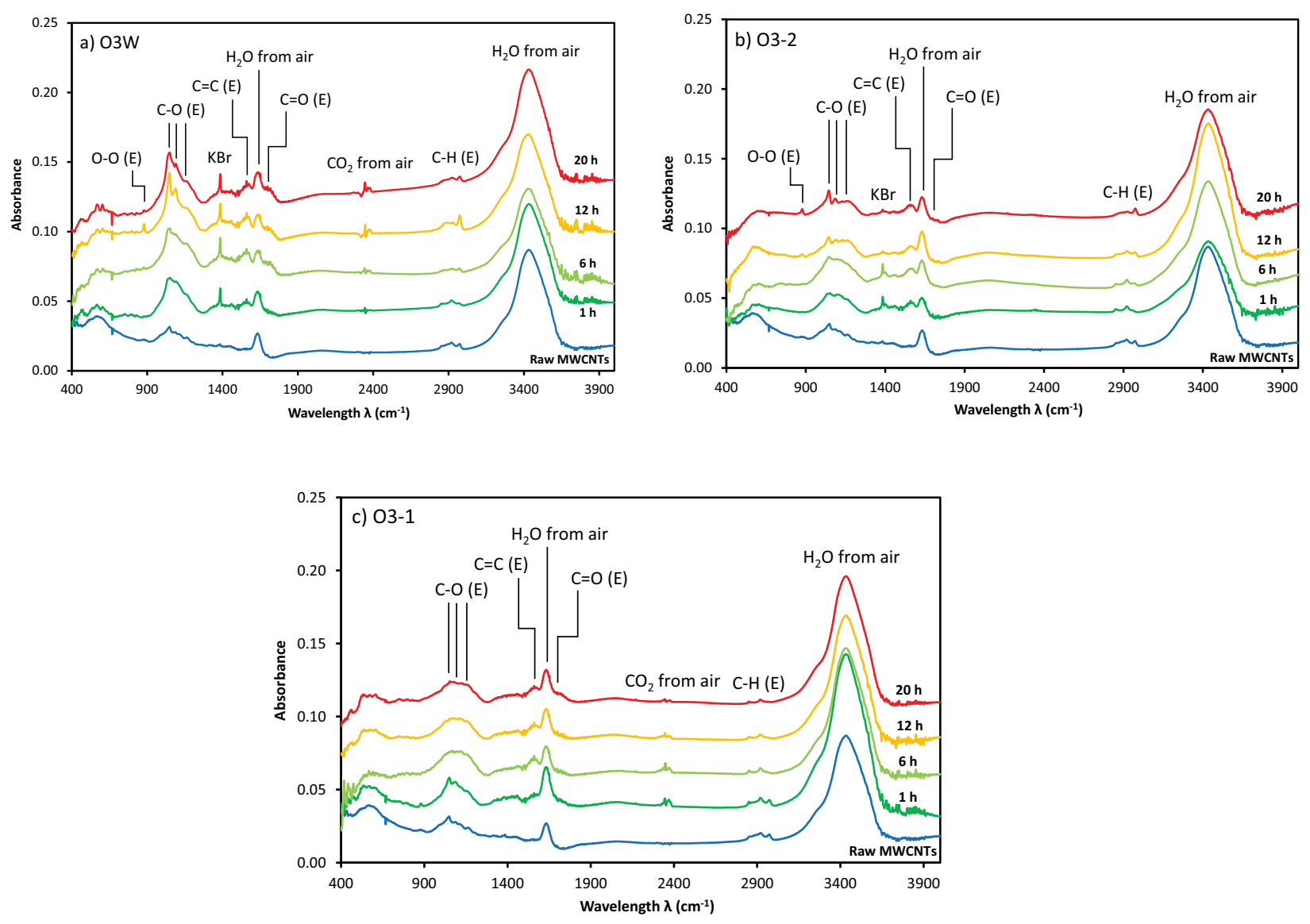

Figure 5. FTIR spectra of (a) run O3W, (b) run O3-2, (c) run O3-1 - (E) means elongation. 
a)
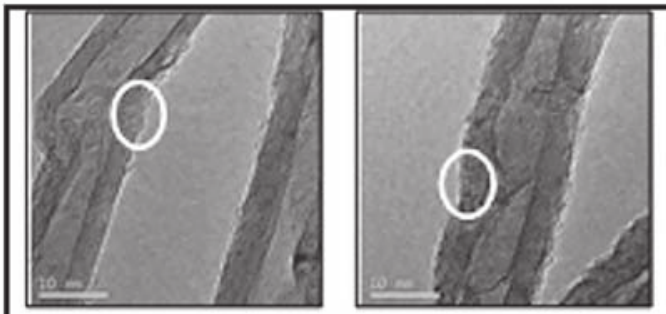

b)
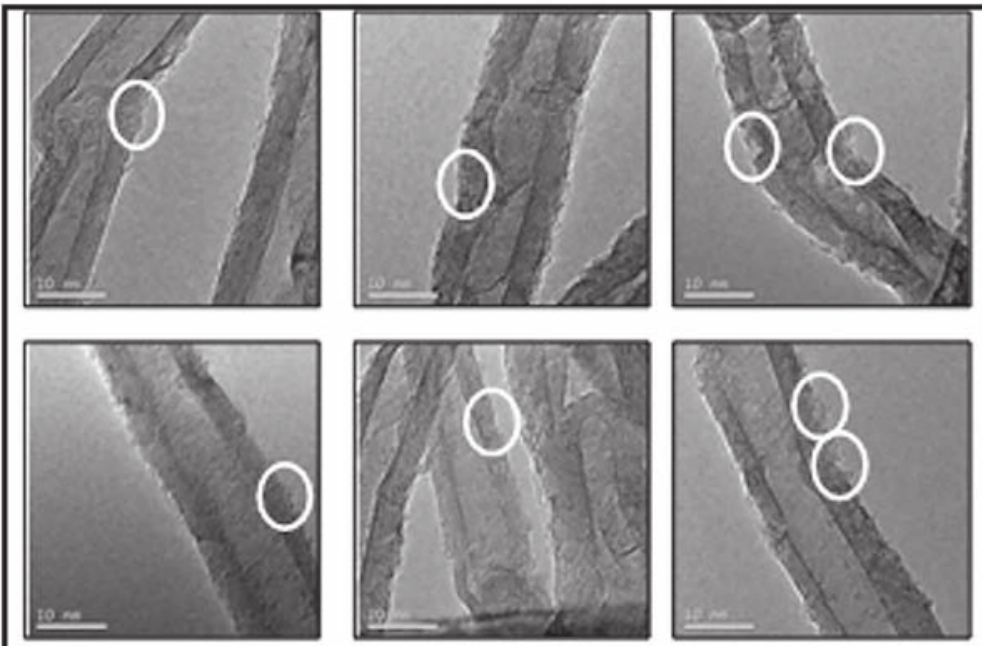

c)
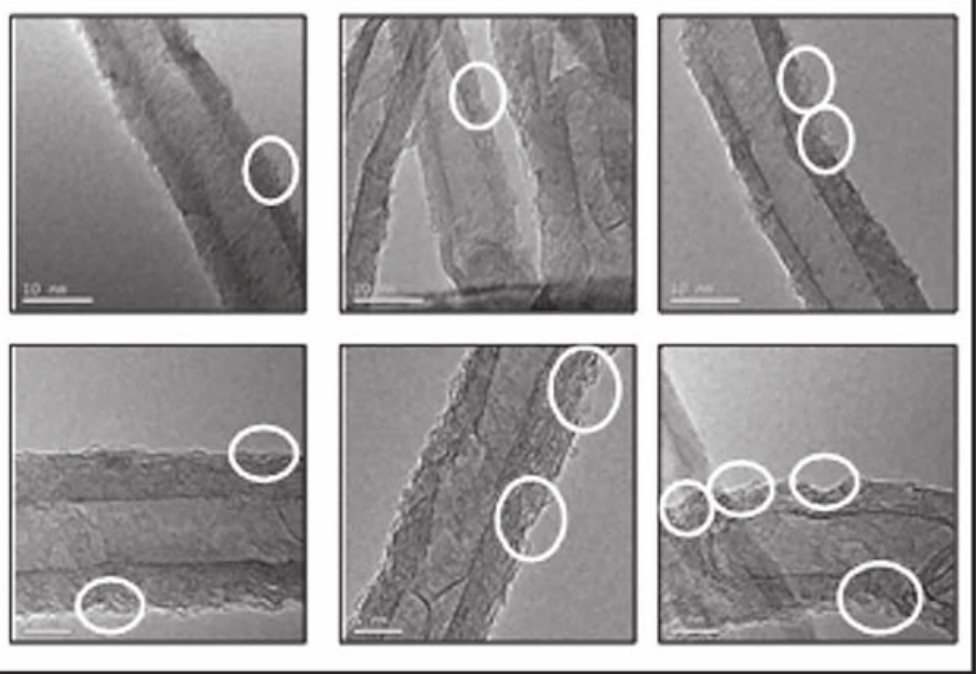

Figure 6. HRTEM results for (a) run O3-1, (b) run O3-2, (c) run $\mathrm{O} 3 \mathrm{~W}$ (the circles show the main defects created).
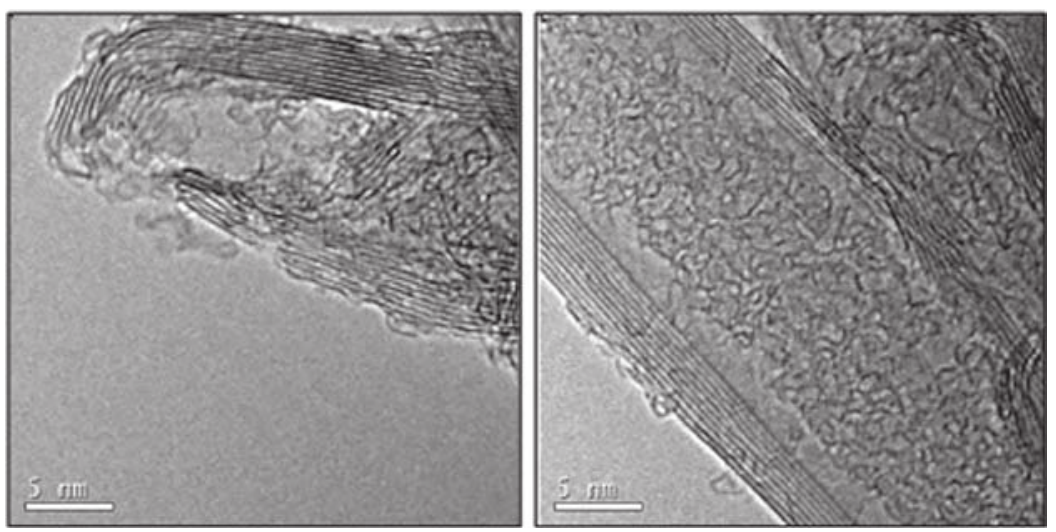

Figure 7. HRTEM images of carbonaceous nano-debris for run $\mathrm{O} 3 \mathrm{~W}$ after $20 \mathrm{~h}$.

For the three conditions tested, it appears that some structural defects are created from the first hour of treatment and that their number seems to increase with the treatment duration. They are formed both on the intrinsic defects of the MWCNTs and along the straight parts of their walls. However, the modification of the MWCNT structure is moderate, even with water vapour: no severe destruction of the walls is observed, contrarily to other authors, in particular Peng et al. ${ }^{[10]}$ who have tested much higher ozone flow rates per unit mass of nanotubes, so more reactive gaseous mixtures.

Indeed, the composition of the gaseous mixture has a clear influence on the final state of MWCNTs. By comparing the images of runs 03-1 (1.7 vol\% of $\left.\mathrm{O}_{3}\right)$ and 03-2 $\left(0.2 \mathrm{vol} \%\right.$ of $\left.\mathrm{O}_{3}\right)$, it seems that an increase of the ozone concentration exalts the formation of structural defects. The addition of water vapour (run $\mathrm{O3W}$ ) intensifies the MWCNT etching, as observed by Peng et al. ${ }^{[10]}$

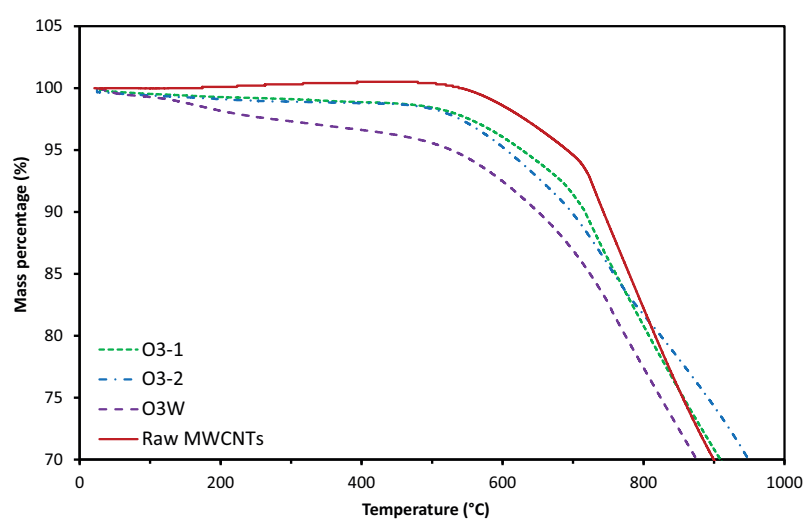

Figure 8. TGA spectra of MWCNTs before and after $6 \mathrm{~h}$ of treatment. 
Table 2. Lost mass percentages under $\mathrm{N}_{2}$ for different temperatures and treatment times deduced from the TGA results - lost mass percentage of the raw MWCNTs subtracted

\begin{tabular}{|c|c|c|c|c|c|}
\hline Run & Treatment time $(\mathrm{h})$ & $\mathrm{T}=250^{\circ} \mathrm{C}$ & $\mathrm{T}=280^{\circ} \mathrm{C}$ & $\mathrm{T}=550{ }^{\circ} \mathrm{C}$ & $\mathrm{T}=650^{\circ} \mathrm{C}$ \\
\hline \multirow[t]{2}{*}{ Raw MWCNTs } & - & 0 & 0 & 0.1 & 3.2 \\
\hline & 1 & 1.0 & 1.1 & 2.6 & 3.1 \\
\hline \multirow[t]{3}{*}{ O3-1 } & 6 & 0.8 & 0.9 & 2.3 & 2.8 \\
\hline & 12 & 1.0 & 1.1 & 3.1 & 3.8 \\
\hline & 1 & 0.3 & 0.4 & 1.2 & 1.8 \\
\hline \multirow[t]{3}{*}{ O3-2 } & 6 & 1.0 & 1.1 & 2.2 & 3.1 \\
\hline & 12 & 1.4 & 1.6 & 3.4 & 4.1 \\
\hline & 1 & 1.1 & 1.2 & 2.7 & 6.6 \\
\hline \multirow[t]{2}{*}{$\mathrm{O} 3 \mathrm{~W}$} & 6 & 2.3 & 2.6 & 5.5 & 6.8 \\
\hline & 12 & 3.5 & 3.8 & 8.1 & 9.8 \\
\hline
\end{tabular}

Indeed, for run $\mathrm{O} 3 \mathrm{~W}$, after $20 \mathrm{~h}$ of treatment, the central cavity of some MWCNTs is open.

Some nano-objects constituted of amorphous carbon (possibly including fullerenes) are present on the outer MWCNT walls after treatment for all the conditions tested. On the other hand, it has been recurrently observed that any amorphous carbon intrinsically present on the outer MWCNT surface is rapidly etched by ozone treatment. ${ }^{[9,14,18]}$ A possible explanation for this residual amorphous carbon is that the nano-debris created by the wall etching can either cover the outer MWCNT walls or be elutriated at the reactor exit. ${ }^{[9,10,37]}$ Such carbonaceous nanodebris have also been detected inside the central cavity of MWCNTs, whatever the treatment type and duration, as illustrated in Figure 7. A possible mechanism is that once a hole is created in the MWCNT wall, the outer amorphous carbon (part of it originating from the etching of the wall) is sucked into the central cavity because the pressure in it is lower than outside. ${ }^{[36]}$ This phenomenon has already been observed for a treatment of MWCNTs under air at $800{ }^{\circ} \mathrm{C} .{ }^{[36]}$

\section{TGA Results}

The TGA curves (Figure 8) were obtained under nitrogen with a temperature increase of $10{ }^{\circ} \mathrm{C} \cdot \mathrm{min}^{-1}$ for the 3 runs after $6 \mathrm{~h}$ of treatment. The thermal stability of MWCNTs is clearly lower after oxidative treatment due to the larger presence of oxygen-containing groups and of structural defects. ${ }^{[8]}$ The raw MWCNTs are quite stable at temperatures up to $550{ }^{\circ} \mathrm{C}$, a value which is slightly lower than for the NC7000 grade MWCNTs from Nanocyl. ${ }^{[8]}$ This could be due to differences in purity and/or in structural quality. For the oxidized MWCNTs, the weight loss occurs till the beginning of the TGA measurements. This is due to the loss of the grafted oxygencontaining groups which, depending on their nature, decompose into $\mathrm{CO}, \mathrm{CO}_{2}$, or $\mathrm{H}_{2} \mathrm{O}$ upon heating. ${ }^{[8,33,38,39]}$

Table 2 presents the amounts of grafted oxygenated groups determined from TGA results obtained at $250{ }^{\circ} \mathrm{C}, 280{ }^{\circ} \mathrm{C}, 550{ }^{\circ} \mathrm{C}$, and $650{ }^{\circ} \mathrm{C}$ for different treatment durations. For each run and each temperature, the mass percentage of grafted functions increases with the treatment time, except for some results of run 03-1, probably due to the heterogeneity of the MWCNT samples. At $650{ }^{\circ} \mathrm{C}$, the slope change observed in Figure 8 means that the MWCNT structure begins to be destroyed. So, we have estimated the total mass percentage of grafted functions from Table 2 results at $550{ }^{\circ} \mathrm{C}$. It appears that the highest mass percentages of grafted functions are obtained for run $\mathrm{O} 3 \mathrm{~W}$ in the presence of water vapour (almost $8 \mathrm{wt} \%$, compared with $3.4 \mathrm{wt} \%$ obtained without water), confirming the positive effect of water vapour to enhance the oxidation process.
According to the literature ${ }^{[33,38,39]}$ it is possible to determine the nature of the oxygen-functions using their decomposition temperature. Below $550{ }^{\circ} \mathrm{C}$, only the carboxylic acids, anhydride, and some carbonyl (aldehyde and ketone) groups are decomposed. By comparing the $03 \mathrm{~W}$ results with the 03-1/03-2 ones, this could mean that in the presence of water vapour (run $\mathrm{O} 3 \mathrm{~W}$ ), the grafted functions are more largely composed of carboxylic acids, anhydride, and carbonyl groups than without water. These conclusions are in agreement with the FTIR results.

After $1 \mathrm{~h}$ at $550{ }^{\circ} \mathrm{C}$, the lowest mass percentage is observed for run $03-2$, which corresponds to the lowest $\mathrm{O}_{3}$ concentration tested without water vapour. However, by comparing the results obtained for runs 03-1 and 03-2, the influence of the ozone inlet concentration disappears from $6 \mathrm{~h}$ of treatment, probably due to the higher fluidization ratio and then to a higher supply of ozone for run 03-2. These values are logically lower than those of the literature for similar durations, ${ }^{\left[{ }^{8-10,14]}\right.}$ because of the lower ozone flow rates used per unit mass of MWCNTs.

Beyond $550{ }^{\circ} \mathrm{C}$, the decomposition of more stable functions (phenol, ether, ester, lactone, and quinone groups) could occur simultaneously with the MWCNT destruction, explaining the massive decrease of weight observed by TGA from this temperature. The difference of mass percentage between $550{ }^{\circ} \mathrm{C}$ and $650{ }^{\circ} \mathrm{C}$ is clearly higher with water (run O3W) than without. This is in agreement with the FTIR results and confirms that the presence of water also exalts the formation of these functions, especially for short treatment durations.

\section{CONCLUSION}

A pre-industrial scale fluidized bed process using ozone-containing gas mixtures at ambient temperature was developed, allowing $100 \mathrm{~g}$ of Graphistrenght ${ }^{\mathrm{R}} \mathrm{C} 100$ multi-walled carbon nanotubes (MWCNTs) tangled in balls of $388 \mu \mathrm{m}$ in Sauter diameter to be treated. An oxidation mechanism in two steps was evidenced, showing the grafting of simple functions such as hydroxyl, phenol, and ether functions in a first step and then of more complex functions such as lactone, quinone, and carboxylic acid groups in a second step. A moderate etching of the MWCNT outer walls was observed, forming nano-holes in the outer nanotube walls. The amount of grafted functions and of structural defects created increased with treatment duration and was significantly enhanced by the presence of water vapour. After $12 \mathrm{~h}$ in the presence of water vapour, the amount of grafted oxygen-containing groups (as measured by TGA at $550{ }^{\circ} \mathrm{C}$ ) was $8.1 \mathrm{wt} \%$, which is more than twice the values without water. All the results obtained showed that the treatment was uniform on the whole MWCNT ball powder of the bed as well as from the outer part to the centre 
of the balls, probably thanks to the high fluidization quality maintained all along the ozone treatment and to the effective diffusion of the active gaseous species inside the porous medium formed by the tangle of MWCNTs.

A clear influence of the oxidation process on the MWCNT surface reactivity was evidenced by depositing copper from copper acetylacetonate by Fluidized Bed Chemical Vapour Deposition. It allowed increasing the number and uniformity of the deposited copper nanoparticles and decreasing their size, as detailed elsewhere. ${ }^{[40]}$

These results demonstrate the ability of the fluidized bed process to uniformly oxidize large amounts of MWCNTs and also its versatility. Indeed, shorter treatment durations could be obtained by using higher ozone concentrations and by optimizing the molar fraction of water vapour. This should allow maximizing the amount of grafted oxygen-based functions for a moderate etching of nanotube walls. This work paves the way for the upscaling of this process to an industrial scale, allowing the oxidation of high weights of MWCNTs in dry mode, by a green and low cost technology operating in a single step, without any release of toxic liquid effluents.

\section{ACKNOWLEDGEMENTS}

This work was supported by the Midi-Pyrénées region and by the French Waspe (Weight Saving for Aerospace Packaging Equipments) FUI project. The authors thank M. Molinier, J. Compain, and E. Prévot from LGC for technical help and ARKEMA for providing the carbon nanotubes.

\section{REFERENCES}

[1] M. Monthioux, "Introduction to Carbon Nanotubes," Carbon Meta-Nanotubes: Synthesis, Properties and Applications, John Wiley \& Sons, Chichester 2011, p. 7.

[2] M. F. L. de Volder, S. H. Tawfick, R. H. Baughman, A. J. Hart, Science 2013, 339, 535.

[3] S. Abdalla, F. Al-Marzouki, A. A. Al-Ghamdi, A. AbdelDaiem, Nanoscale Res. Lett. 2015, 10, 2.

[4] Z. Spitalsky, D. Tasis, K. Papagelis, C. Galiotis, Prog. Polym. Sci. 2010, 35, 357.

[5] Q. Zhang, J. Q. Huang, W. Z. Qian, Y. Y. Zhang, F. Wei, Small 2013, 9, 1237.

[6] F. Morales-Lara, M. J. Perez-Mendoza, D. Altmajer-Vaz, M. Garcia-Roman, M. Melguizo, F. J. Lopez-Garzon, M. Domingo-Garcia, J. Phys. Chem. C 2013, 117, 11647.

[7] L. C. Tang, H. Zhang, J. H. Han, X. P. Wu, Z. Zhang, Compos. Sci. Technol. 2011, 72, 7.

[8] J. H. Kim, B. G. Min, Carbon Lett. 2010, 11, 298.

[9] H. Xia, Y. Zhang, C. Chen, W. Wu, K. Yao, J. Zhang, J. Mater. Sci. Technol. 2016, 32, 533.

[10] K. Peng, L. Q. Liu, H. Li, H. Meyer, Z. Zhang, Carbon 2011, 49, 70 .

[11] V. Datsyuk, M. Kalyva, K. Papagelis, J. Parthenios, D. Tasis, A. Siokou, I. Kallitsis, C. Galiotis, Carbon 2008, 46, 833.

[12] B. Scheibe, E. Borowiak-Palen, R. J. Kalenczuk, Mater. Charact. 2010, 61, 185.

[13] Y. Peng, H. Liu, Ind. Eng. Chem. Res. 2006, 45, 6483.

[14] D. C. Vennerberg, R. L. Quirino, Y. Jang, M. R. Kessler, ACS Appl. Mater. Inter. 2014, 6, 1835.
[15] M. Q. Tran, C. Tridech, A. Alfrey, A. Bismarck, M. S. P. Shaffer, Carbon 2007, 45, 2341.

[16] W. Xia, C. Jin, S. Kundu, M. Muhler, Carbon 2009, 47, 919.

[17] C. Li, A. Zhao, W. Xia, C. Liang, M. Muhler, J. Phys. Chem. C 2012, 116, 20930.

[18] H. Rong, Z. Liu, Q. Wu, Y. H. Lee, Curr. Appl. Phys. 2010, 10,1231 .

[19] E. Najafi, J. Y. Kim, S. H. Han, K. Shin, Colloid. Surface. A 2006, 284-285, 373.

[20] H. Yu, Q. Zhang, G. Gu, Y. Wang, G. Luo, F. Wei, AIChE J. 2006, 52, 4110.

[21] K. Dasgupta, J. B. Joshi, S. Banerjee, Chem. Eng. J. 2011, 171,841 .

[22] C. Vahlas, B. Caussat, P. Serp, G. N. Angelopoulos, Mat. Sci. Eng. R. 2006, 53, 1.

[23] A. Suri, K. S. Coleman, Carbon 2011, 49, 3031.

[24] D. Kunii, O. Levenspiel, Fluidization engineering, $2^{\text {nd }}$ edition, Butterworth-Heinemann, Oxford 1991.

[25] A. R. Barron, Ed., Physical methods in chemistry and nanoscience, Rice University, Houston 2012, URL: http:// cnx.org/content/col10699/1.18/.

[26] M. Leturia, K. Saleh, Fluidisation gaz-solide - bases et théorie, J4100 V2, Techniques de l'Ingénieur, Saint-Denis 2014, p. 30.

[27] W. Li, Y. Bai, Y. K. Zhang, M. L. Sun, R. M. Cheng, X. S. Xu, Y. Chen, Y. Mo, Synthetic Met. 2005, 155, 509.

[28] R. Tian, X. Wang, M. Li, H. Hu, R. Chen, F. Liu, H. Zheng, L. Wan, Appl. Surf. Sci. 2008, 255, 3294.

[29] M. J. Rahman, T. Mieno, J. Nanomater. 2014, 2014, 1.

[30] J. Zhang, H. Zou, Q. Qing, Y. Yang, Q. Li, Z. Liu, X. Guo, Z. Du, J. Phys. Chem. B 2003, 107, 3712.

[31] D. Mawhinney, V. Naumenko, A. Kuznetsova, J. T. Yates, J. Liu, R. E. Smalley, J. Am. Chem. Soc. 2000, 122, 2383.

[32] P. C. Ma, J. K. Kim, B. Z. Tang, Carbon 2006, 44, 3232.

[33] J. L. Figueiredo, M. F. R. Pereira, M. M. A. Freitas, J. J. M. Órfão, Carbon 1999, 37, 1379.

[34] M. V. Naseh, A. A. Khodadadi, Y. Mortazavi, F. Pourfayaz, O. Alizadeh, M. Maghrebi, Carbon 2010, 48, 1369.

[35] I. P. Japokovic, S. Kapic, S. Alihodzic, V. Sunjic, Arkivoc 2015, 2015, 300.

[36] P. M. Ajayan, T. W. Ebbesen, T. Ichihashi, S. Iijima, K. Tanigaki, H. Hiura, Nature 1993, 362, 522.

[37] R. Verdejo, S. Lamoriniere, B. Cottam, A. Bismarck, M. Shaffer, Chem. Commun. 2007, 2007, 513.

[38] S. Kundu, Y. Wang, W. Xia, M. Muhler, J. Phys. Chem. C 2008, 112, 16869

[39] R. W. Gosselink, R. van den Berg, W. Xia, M. Muhler, K. P. de Jong, J. H. Bitter, Carbon 2012, 50, 4424.

[40] P. Lassègue, Oxydation en lit fluidisé et dépôt de métaux par CVD en lit fluidisé sur nanotubes de carbone multi-parois Application à l'industrie aéronautique, $\mathrm{PhD}$ thesis, Institut national polytechnique de Toulouse, Toulouse 2016, p. 161. 